\title{
É tarde demais para nos calar: o feminismo nas esferas públicas midiáticas
}

\author{
Anna Vitória Ferreira Rocha \\ Adriana C. Omena Santos ${ }^{2}$
}

\begin{abstract}
Resumo: $\bigcirc$ trabalho analisou a presença do movimento feminista nas esferas públicas da sociedade, com foco na esfera pública abstrata formada pelos meios de comunicação. O corpus é composto pelo caso Think Olga ao usar a hashtag ${ }^{3}$ \#primeiroassedio. A escolha se deu devido à repercussão obtida pela iniciativa que manifestações femininas a partir do ângulo que considera a mobilização feita por esferas públicas feministas na internet a grande catalisadora dos protestos e campanhas vivenciados no país entre 2011 e 2015. As informações são analisadas a partir do método dialético, que confronta principalmente dados históricos e contraditórios do fenômeno, e para tanto usaremos como pressupostos teóricos o arcabouço conceitual do feminisno e os conceitos de esfera pública formulados por Habermas e criticados por Nancy Fraser. Os resultados mostram que a internet se coloca como veículo que permite ao feminismo um alcance extraordinário, obtendo o interesse dos grandes veículos de comunicação, sem, no entanto, criar um novo movimento feminista.
\end{abstract}

Palavras-chave: Feminismo. Esfera Pública. Esfera Pública Midiática. Internet. Feminismo Virtual.

\begin{abstract}
This work analyses feminism inside the public spheres of society, focusing on the abstract public sphere constructed by the media. The corpus is composed by the case of the website Think Olga and its use of the hashtag \#firstharassment. This choice is justified by the repercussion that feminist publications online gained in the last few years and the way many considered them as the main ignition for the protests and manifestations that happened in Brazil between 2011 and 2015. The data was analysed using the dialetic method, confronting history and contradictions found in the objects. Doing so, we used the feminist theory as well as the concept of public sphere posed by Jürgen Habermas and criticized by Nancy Fraser. The results show that we can consider the internet as a medium that allows feminism an extraordinary reach, being able to get the interest of the big vehicules of communication, without creating a new feminism whatsoever.
\end{abstract}

'Bacharel em Comunicação Social: Jornalismo pela Universidade Federal de Uberlândia, mestranda na Escola de Comunicações e Artes da Universidade de São Paulo (ECA/USP). email: rocha.annavitoria@gmail.com.

${ }^{2}$ Orientadora do trabalho. Doutora em Comunicação pela ECA/USP, docente do Programa de Pós-Graduação Tecnologias, Educação e Comunicação e do curso de Comunicação Social: Jornalismo da Faculdade de Educação da Universidade Federal de Uberlândia (UFU), e-mail: adriana.omena@.ufu.br.

${ }^{3}$ Ferramenta utilizada para indexar conteúdo nas redes sociais. Ao usar o símbolo da cerquilha (\#) junto de alguma palavra-chave, cria-se um hiperlink que unirá aquele conteúdo a tudo que já foi postado a respeito do tema na plataforma. 
Keywords: Feminism. Public Sphere. Mediatic Public Sphere. Online Feminism. Internet.

Resumen: El presente trabajo analizó la presencia del movimiento feminista en las esferas públicas de la sociedad, con foco en la esfera pública abstracta formada por los medios de comunicación. El corpus se compone del caso Think Olga y el uso del hashtag \#primeiroassedio. La elección se dio debido a la repercusión obtenida por la iniciativa de las manifestaciones femeninas desde el ángulo que considera la movilización hecha por esferas públicas feministas en internet, la gran catalizadora de las protestas y campañas vivenciadas en el país entre 2011 y 2015. Las informaciones recogidas se analizan a partir del método dialéctico, que coloca de frente principalmente datos históricos y contradictorios del fenómeno, y para tanto usaremos como presupuestos teóricos el marco conceptual del feminismo y los conceptos de esfera pública formulados por Habermas y criticados por Nancy Fraser. Los resultados muestran que Internet se sitúa como vehículo que permite al feminismo un alcance extraordinario, obteniendo el interés de los grandes medios de comunicación, sin, sin embargo, crear un nuevo movimiento feminista.

Palabras clave: Feminismo. Esfera Pública. Esfera Pública Midiática. Internet. Feminismo Virtual.

\section{Introdução}

O movimento feminista vive um período de destaque, sendo tema de conversa e alcançando cada vez mais pessoas. No Exame Nacional do Ensino Médio (Enem) de 2015, o tema da redação foi a persistência da violência contra a mulher, e Simone de Beauvoir foi referência em uma das questões da prova. Não é preciso ser feminista ou apoiar o movimento para discorrer sobre a violência contra a mulher, mas é inegável que a escolha do tema - de uma prova que ano após ano visa abordar questões atuais em pauta na sociedade - tem a ver com todo o debate iniciado nas esferas públicas feministas, que foi capaz de extrapolar seu nicho restrito e ocupar novos espaços.

Este alcance extraordinário vem graças à nova posição que o movimento ocupa na esfera pública brasileira. Se antes ele se restringia a reuniões privadas, coletivos universitários e meios de comunicação próprios que falavam apenas para seu público já conquistado, atualmente o feminismo tem potencializado sua esfera midiática própria, gerando uma mobilização que o impulsiona além, ocupando espaços nos meios de comunicação de massa, tematizando a esfera pública das conversas nas ruas, conscientizando meninas cada vez mais jovens, chegando até mulheres que sofreram com a opressão a vida toda, mas não sabiam que nome dar para o seu problema - muito menos que havia outras mulheres passando por ele. O feminismo também chegou à esfera pública política, levando suas causas para debate nas esferas de poder na luta por mais direitos e pela manutenção daqueles já adquiridos, ainda ameaçados.

\section{Feminismo e publicações feministas}

A escritora nigeriana Chimamanda Ngozi Adichie (2014, s.p.) atribui sua definição básica de feminista ao dicionário: "uma pessoa que acredita na igualdade social, política e econômi- 
ca entre os sexos.". É importante destacar que os objetivos do movimento feminista dizem respeito não apenas à igualdade social, econômica e política entre os sexos, mas também à igualdade de poder fazer uso da liberdade para escolher quem se quer ser, em que todas as possibilidades são permitidas em qualquer que seja o país.

A respeito da história do movimento no Brasil, a historiadora Céli Regina Jardim Pinto (2003, p. 9) afirma que o movimento "tem sido por natureza um movimento fragmentado, com múltiplas manifestações, objetivos e pretensões diversas. Sua história, desde os primeiros momentos [...] foi pautada por essa multiplicidade, em que os momentos unitários foram efêmeros e com objetivos muito específicos.".

É importante, primeiramente, diferenciar os movimentos de mulheres de movimentos feministas. Maria Amélia de Almeida Teles (1993) separa os dois da seguinte maneira: o primeiro busca, dentre outras coisas, mais direitos e melhores condições de trabalho sem problematizar, necessariamente, a questão de gênero.

Para o feminismo, no entanto, essas demandas são, sim, um problema de gênero, e, de acordo com Adichie (2014, s.p.), seria até "desonesto" não reconhecê-lo, pois, segundo ela:

\begin{abstract}
Por que não dizer que você acredita nos direitos humanos ou algo parecido? Porque seria desonesto. O feminismo faz, obviamente, parte dos direitos humanos de uma forma geral - mas escolher uma expressão vaga como 'direitos humanos' é negar a especificidade e particularidade do problema de gênero. Seria uma maneira de fingir que as mulheres não foram excluídas ao longo dos séculos. Seria negar que a questão de gênero tem como alvo as mulheres. Que o problema não é o ser humano, mas especificamente um ser humano do sexo feminino. (ADICHIE, 2014, s.p.)
\end{abstract}

Assim, os movimentos feministas consideram a problemática de gênero como intrínseca a outros setores da vida em sociedade, e, para Teles (1993, p. 12), ele é feito por "mulheres que combatem a discriminação e a subalternidade e que criam meios para que as mulheres sejam protagonistas de suas vidas e história.".

A história do movimento feminista pode ser organizada também por meio de ondas ou fases. No entanto, como destaca Marília Moschkovich (2014, s.p.):

As 'ondas', ao contrário do que algumas pessoas podem imaginar, não são determinadas por um critério cronológico, mas pelo pensamento feminista, pelas reivindicações e pela elaboração da teoria feminista que aconteceram em cada época. 0 início de uma 'nova onda' não implica no fim imediato da anterior. Sendo assim, hoje temos gente que defende pensamentos e bandeiras que consideramos como sendo da terceira onda, mas também há quem defenda esquemas de pensamento ligados à segunda onda e até mesmo à primeira. (MOSCHKOVICH, 2014, s.p.)

Deste modo, a primeira onda do feminismo pode ser identificada como luta pela igualdade política, ligada principalmente ao movimento sufragista, que reivindicava o voto feminino. De acordo com Narvaz e Koller (2006, p. 649), "O objetivo do movimento feminista, nessa época, era a luta contra a discriminação das mulheres e pela garantia de direitos, inclusive do direito ao voto.".

A segunda onda tem início em meados dos anos 60 e apresenta grande força principalmente nos Estados Unidos e na França. Em 1949 Simone de Beauvoir escreve e publica o segundo Sexo, trabalho no qual ela apresenta e questiona "em que o fato de sermos mulheres terá afetado a nossa vida? Que possibilidades nos foram oferecidas, exatamente, 
e quais nos foram recusadas? Que destino podem esperar nossas irmãs mais jovens?" (BEAUVOIR, 1970, p. 22).

Ela fala, sobretudo, a partir da experiência de um ser que

[...] sendo, como todo ser humano, uma liberdade autônoma, descobre-se e escolhe-se num mundo em que os homens the impõem a condição do Outro. [...] O drama da mulher é esse conflito entre a reivindicação fundamental de todo sujeito que se põe sempre como o essencial e as exigências de uma situação que a constitui como inessencial. (BEAUVOIR, 1970, p. 23)

São as diferentes experiências femininas que serão problematizadas pela terceira onda do movimento, que teve influências pós-estruturalistas e foi marcada pelo pensamento de Michel Foucault e Jacques Derrida. Esta nova "proposta concentra-se na análise das diferenças, da alteridade, da diversidade e da produção discursiva da subjetividade. [...] desloca-se o campo do estudo sobre as mulheres e sobre os sexos para o estudo das relações de gênero." (NAVAZ; KELLER, 2006, p. 649).

Nesta fase, chamada de interseccional, entende-se que ser mulher não é uma experiência universal, e por isso é preciso levar em conta as demandas e contextos específicos de cada uma, pensando a partir de outras categorias de análise, principalmente as de raça e classe.

Os estudos de Pinto (2003) narram a história do feminismo brasileiro até o início do século XXI e sua conclusão é de que o movimento não existe mais na forma como se manifestava principalmente nas décadas de 1960 e 1970, e isso vale tanto para o Brasil como para a Europa e os Estados Unidos. Ela frisa, no entanto, que isso não significa que o feminismo parou nesse período, apenas que assumiu diferentes formas. No caso local, era possível percebê-lo em ações fragmentadas, não necessariamente identificadas como feministas, mas que sempre estiveram incorporadas à militância feminista. A autora cita como exemplo as discussões sobre piadas machistas (racistas e homofóbicas também), não mais tão aceitas socialmente, e debates e mobilizações contra o assédio sexual.

No intervalo que compreende o fim da pesquisa de Pinto (2003) e o momento atual, o principal que se pode destacar é a internet como fator de fortalecimento da luta, tanto para a conscientização das mulheres, como na criação de grupos de apoio e também de organização política para ações sociais. Além disso, chama atenção a proliferação de sites e blogs voltados ao tema. Isso, no entanto, não constitui uma novidade. O feminismo sempre se valeu dos meios de comunicação para difundir suas ideias. A imprensa especializada feminista foi um importante vetor na propagação de ideais e levou a cartilha feminista ao alcance de mais mulheres ao longo do século XX. Teles (1993, p. 33) registra que o "Brasil foi o país latino-americano onde houve maior empenho do jornalismo feminista".

Marília Moschkovich (2014) aponta, porém, que a internet não inventou práticas novas, apenas ampliou seu alcance, por isso não seria correto chamar esse movimento de "novo feminismo", posto que as fases do feminismo são demarcadas por mudanças de pensamento ou correntes teóricas

\section{Reflexões acerca da(s) esfera(s) pública(s) em Habermas}

O espaço coletivo onde se constroem e se propagam os discursos é a esfera pública. Inicialmente, Habermas (2003) compreende a esfera pública como um produto do Estado mo- 
derno burguês, cuja ascensão provocou a cisão entre os domínios públicos e privados da vida em sociedade. Com intuito de auxiliar a conceituação acerca do termo é possível apresentar as considerações de Fernando Perlatto (2012, p. 80), que explica a esfera pública como um

\begin{abstract}
[...] novo espaço situado entre a esfera privada e o Estado, caracterizado pela discussão livre e racional e no qual as opiniões se legitimariam não mais a partir de fatores sociais externos - como poder, riqueza e prestígio -, mas através de argumentos racionais sustentados em meio ao debate público. A emergência da esfera pública somente será possível a partir da separação entre os interesses vinculados à economia doméstica e a subjetividade, que permitirá o desacoplamento da capacidade reflexiva dos indivíduos da sua respectiva esfera dos interesses materiais. (PERLATTO, 2012, p. 80)
\end{abstract}

Neste período, a imprensa se estabelece como instituição da esfera pública (Habermas 2003), evoluindo de um sistema de troca de informações comerciais para "uma imprensa de opinião em que um jornalismo literário passou a concorrer com a mera redação de avisos.' (HABERMAS, 2003, p. 214).

Uma parte significativa das críticas ao trabalho de Habermas diz respeito ao caráter excludente de sua concepção de esfera pública. Nancy Fraser (1990) é uma das autoras que val fazer o trabalho de repensar a formulação do autor a respeito desse conceito. A teórica aponta Joan Landes (1988) como responsável pela conclusão de que "o eixo chave da exclusão é o de gênero" (Fraser, 1990, p. 59, tradução nossa4).

Outro ponto frágil no trabalho de Habermas, de acordo Fraser, é sua falha em admitir a existência de outras esferas públicas, formada pelos grupos excluídos pelos burgueses.

[...] o problema não é só que Habermas idealiza a esfera pública, mas ele também deixa de examinar outras, não-liberais, não-burguesas, esferas públicas concorrentes. Ou, ainda, é precisamente porque ele deixa de examinar essas outras esferas públicas que ele acaba por idealizar a esfera pública liberal. (FRASER, 1990, p. 60-61 tradução nossa ${ }^{5}$.

Fraser pontua que o teórico não negava ou ignorava a existência de outras esferas, mas acreditava que a esfera pública burguesa era suficiente para se apreender o conceito da esfera pública, existindo de forma isolada na sociedade.

Ao longo de seus outros trabalhos Habermas retornou ao conceito de esfera pública, revisando-o de modo a adaptá-lo às organizações sociais mais recentes. Em Direito e Democracia: Entre Facticidade e Validade, o autor define esfera pública como: "uma rede adequada para a comunicação de conteúdo, tomadas de posição e opiniões; nela os fluxos comunicacionais são filtrados e sintetizados, a ponto de se condensarem em opiniões públicas enfeixadas em temas específicos" (HABERMAS, 1997, p. 92, grifos do autor).

4 "[...] the key axis of exclusion is gender" (FRASER, 1990, p. 59).

$5[. .$.$] the problem is not only that Habermas idealizes the liberal public sphere but also that He fails to$ examine other, nonliberal, nonbourgeois, competing public spheres. Or rather, it is precisely because he fails to examine these other public spheres that he ends up idealizing the liberal public sphere. (FRASER, 1990, p. 60-61) 
Com essa definição ele desloca a esfera pública do contexto histórico e material do mundo burguês para entendê-lo como algo mais amplo, que diz respeito diretamente à capacidade dos homens de comunicar-se entre si a respeito de assuntos que têm a ver com a coletividade.

Numa configuração atualizada, ao falar da formação da opinião pública o autor reforça a importância da deliberação racional dos pontos de vista presentes. Habermas (1997, p. 94) é enfático ao afirmar que a opinião "só se forma como resultado de uma controvérsia mais ou menos ampla, na qual propostas, informações, argumentos podem ser elaborados de forma mais ou menos racional." Tal conceito tem sido bastante questionado na atualidade se consideramos as temáticas da situação feministas, principalmente em ambientes virtuais.

Outro ponto que vale a pena ser visitado nesta concepção atualizada que o autor constrói sobre a esfera pública diz respeito à maneira como ele enxerga subdivisões dentro dela. Além de permitir que a esfera pública assuma ramificações diversas, especializando-se em temas funções e especificidades (o feminismo, por exemplo, é reconhecido como parte da trama dessa rede complexa descrita por Habermas), ele também diferencia a esfera pública a partir de "níveis, de acordo com a densidade da comunicação, da complexidade organizacional e do alcance" (HABERMAS, 1997, p. 107).

Essa divisão dará origem a três esferas públicas:

Esfera pública episódica (bares, cafés, encontros de rua), esfera pública da presença organizada (encontros de pais, público que frequenta o teatro, concertos de rock reuniões de partido ou congressos de igreja) e esfera pública abstrata, produzida pela mídia (leitores, ouvintes, espectadores singulares e espalhados globalmente). Apesar dessas diferenciações, as esferas públicas parciais, constituídas através da linguagem comum ordinária, são porosas, permitindo uma ligação entre elas. (HABERMAS 1997, p. 107, grifos do autor)

Antes disso, contudo, é importante entender um pouco mais sobre os componentes destas esferas, visto que eles também se atualizam a partir do momento que Habermas deixa de ter a sociedade burguesa como foco em sua análise. Deste modo, sua concepção anterior de esfera pública era formada por uma sociedade civil - constituída através do direito privado e dirigida através do trabalho, do capital e dos mercados de bens (HABERMAS, 1997, p. 99).

Em seus estudos posteriores, o conceito de sociedade civil passa a fazer referência aos

[...] movimentos, organizações e associações, os quais captam os ecos dos problemas sociais que ressoam nas esferas privadas, condensam-nos e os transmitem, a seguir, para a esfera pública política. O núcleo da sociedade civil forma uma espécie de associação que institucionaliza os discursos capazes de solucionar problemas transformando-os em questões de interesse geral no quadro de esferas públicas. (HABERMAS, 1997, p. 99)

É importante entender que a revisão conceitual demonstra que as fronteiras entre as esferas público e privada já não são mais tão sólidas, num sentido de que a experiência de um cidadão enquanto pessoa privada - aqui se referindo especificamente a respeito dos problemas sociais enfrentados cotidianamente - se conecta primeiro com a de outras pessoas que fazem parte de sua esfera privada (família, amigos, vizinhos, colegas de trabalho), a qual o autor chama de "densa rede de interações" (HABERMAS, 1997, p. 98), podendo ser expandida para outras pessoas, se tornando, então, pública. 
Isso ocorre uma vez que os canais de comunicação da esfera pública engatam-se nas esferas da vida privada (HABERMAS, 1997, p. 98), levando as questões discutidas e vividas de modo privado a receber um alcance maior, ecoando em experiências que podem ser universais ou pelo menos compartilhadas por um número maior de pessoas que se conecta pelas condições diferenciadas em que se dá a comunicação. Com isso, o autor elabora mais um importante ponto a respeito da esfera pública: "A esfera pública retira seus impulsos da assimilação privada de problemas sociais que repercutem nas biografias particulares" (HABERMAS, 1997, p. 98).

É justamente por se vincular à esfera privada da vida que tal sociedade civil se posiciona de forma independente de estruturas econômicas e governamentais, unindo-se por um componente fundamentalmente social.

\section{Discussão e resultados - o caso Think Olga}

Para melhor ilustrar algumas das considerações feitas até agora, vamos nos valer do caso da jornalista Juliana de Faria, criadora do coletivo feminista Think Olga6. Em outubro de 2015, a edição infantil do Masterchef Júnior, reality show de competição culinária, gerou burburinho nas redes sociais por conta dos comentários de teor sexual proferidos a respeito de uma das participantes, uma menina de 12 anos de idade. Observando essa reação, Faria lançou no Twitter a hashtag? \#primeiroassedio, convidando as mulheres a compartilhar histórias da primeira vez em que foram assediadas sexualmente por homens.

De acordo com dados divulgados no Think Olga, em menos de uma semana a hashtag foi publicada mais de 82 mil vezes. A métrica publicada pelo jornalista Rafael Kenski (2015), que também analisou os dados, revela que no dia em que foi lançada a hashtag chegou a agregar sete mil mensagens por hora.

A iniciativa virou notícia nos principais veículos de comunicação do país, tanto em plataformas digitais como em plataformas impressas, chamando atenção também de órgãos do governo federal, como o Portal Brasil, que usou a hashtag para reforçar sua campanha contra o abuso sexual e divulgar os canais de denúncia, bem como a Unicef, que endossou a campanha e também divulgou ferramentas de denúncia. A repercussão foi tamanha que a campanha alcançou outros países, como Inglaterra, Estados Unidos, Holanda, Chile, Dinamarca, dentre outros, e agora a hashtag traduzida para o inglês (\#firstharassment) tem sido usada para que mulheres do mundo todo compartilhem também suas histórias de assédio sexual na infância.

A partir deste exemplo, é possível observar na prática alguns apontamentos feitos por Habermas e descritos anteriormente: ao convidar as mulheres a compartilhar suas histórias em uma rede social, Juliana de Faria trouxe uma questão antes pertencente a uma esfera privada diretamente para o centro da esfera pública, articulando um problema social a partir da bio-

${ }^{6}$ O Think Olga se define como um think thank feminista cujo objetivo é produzir conteúdo a respeito de mulheres que respeite sua complexidade, visando empoderar mulheres por meio da informação. Criado em 2013, ele pode ser acessado através do endereço: <http://thinkolga.com>. Acesso em 22 mai. 2017.

${ }^{7}$ Ferramenta utilizada para indexar conteúdo nas redes sociais. Ao usar o símbolo da cerquilha (\#) junto de alguma palavra-chave, cria-se um hiperlink que unirá aquele conteúdo a tudo que já foi postado a respeito do tema na plataforma. 
grafia particular de membros da sociedade civil. A dimensão alcançada por sua ação fez com que o tema chamasse a atenção dos veículos de comunicação de massa, e o impacto deste debate na esfera pública política é algo que ainda está se desenvolvendo.

No entanto, podemos questionar se, de fato, apenas os grandes veículos de comunicação de massa compõem a esfera pública das mídias. Messiluce da Rocha Hansen (2009, p. 205) defende que é possível ir além, contemplando neste universo: "as pequenas mídias utilizadas pelos movimentos sociais e outras organizações da sociedade civil não apenas para fins de mobilização social, mas também como forma de participação na comunicação geral e no discurso público tecnicamente mediado.". Segundo a autora, tais meios alternativos são o canal encontrado por grupos menores (em sua maioria, marginalizados) para difundir suas ideias e também contribuir na construção de uma opinião pública cujo discurso confronte muitas vezes aquele propagado de forma pretensamente hegemônica pelos grandes veículos.

A partir destes conceitos, entendemos que Juliana de Faria, com seu coletivo feminista Think Olga, com base fixada na internet, faz parte dessa esfera midiática alternativa juntamente com outros sites e blogs independentes que têm usado da internet para debater o feminismo, ampliar seu alcance, e também incitar ações sociais na esfera pública política.

Hansen (2009, p. 207), no entanto, não considera necessariamente a internet como veículo destinado a descentralizar a esfera pública midiática, devido ao fato de que o "grau de penetrabilidade da Internet nas classes de baixa renda ou, mesmo, nos países subdesenvolvidos e em desenvolvimento ainda é restrito". Para chegar a essa conclusão, a autora se baseou em dados de uma pesquisa realizada em 2008, mais especificamente o estudo do "Uso das Tecnologias da Informação e da Comunicação no Brasil em 2008", realizada pelo Comitê Gestor da Internet no Brasil (2008).

Mesmo assim, a expressividade de alguns dados não pode ser ignorada. De acordo com dados divulgados por pesquisa feita pelo Think Olga em parceria com a Agência Ideal (2015) que monitora influência e engajamento de marcas, o interesse em torno da palavra "feminismo", medido através do número de vezes que a palavra foi pesquisada no Google, e a quantidade de vezes que apareceu em notícias, sites e blogs, foi de 18.100 em outubro de 2014 para 90.500 em outubro de 2015, quando pautas feministas apareceram na prova do Enem. Já o termo "empoderamento feminino" teve aumento de $137 \%$ no que diz respeito ao conteúdo produzido com essa palavra em textos de veículos tradicionais e blogs, com 354\% de aumento no número de buscas do termo no Google. Entre novembro de 2015 e novembro de 2015, o interesse pela expressão foi de 880 para 3.600, sendo que em janeiro de 2014 era apenas de 70.

É preciso considerar nesses números também todas as reações negativas aos termos. Em Backlash, Susan Faludi (2001) mostra a forma como, historicamente, todas as ondas de avanços do feminismo e dos direitos da mulher geram como consequência um contra-ataque, tanto no que tange à restrição de direitos como também nas viradas de opinião pública, e os ataques de grupos que sentem atingidos por aquelas mensagens. Assim, o aumento do interesse acerca de tais termos nas redes não pode ser interpretado unicamente como positivo.

\section{Conclusões - Novo feminismo?}

Vivemos um momento em que todo assunto, cada temática, ganha repercussão imediata e de dimensões inesperadas em ambiente virtual, notadamente nas mídias sociais, tidas como esferas públicas abstratas, porém com viés de episódicas. Tal capacidade de tematizar a esfera pública segue um modelo que Habermas (1997, p. 113) chama de "modelo de 
iniciativa externa", a partir do qual um grupo que está fora do sistema político consegue trazer à tona uma questão a partir da mobilização e pressão da opinião pública. 0 autor, no entanto, associa esse modelo a algo extraordinário, possível apenas em sociedades mais igualitárias, e aponta que normalmente a escolha de temas a serem tratados na esfera pública parte do centro para a periferia (estando no centro os sistemas políticos e de poder, e na periferia a sociedade civil).

Ao falar sobre novos movimentos sociais, espaço que cabe ao feminismo, Habermas (1997, p. 103), baseando-se em Cohen e Arato (1992), descreve suas estruturas como ações ao mesmo tempo defensivas e ofensivas:

\begin{abstract}
Através de uma ofensiva, eles tentam lançar temas de relevância para toda a sociedade, definir problemas, trazer contribuições para a solução de problemas, acrescentar novas informações, interpretar valores de modo diferente, mobilizar bons argumentos, denunciar argumentos ruins, a fim de produzir uma atmosfera consensual capaz de modificar os parâmetros legais de formação da vontade política e exercer pressão sobre os parlamentos, tribunais e governos em benefício de certas políticas Ao passo que defensivamente eles tentam preservar certas estruturas da associação e da esfera pública, produzir contra-esferas públicas subculturais e contra-instituições, solidificar identidades coletivas e ganhar novos espaços na forma de direitos mais amplos e instituições reformadas. (Grifos nossos).
\end{abstract}

Apesar de reconhecer a sensibilidade que tais organizações possuíam com relação aos problemas sociais, para o autor "os sinais que emitem e os impulsos que fornecem são, em geral, muito fracos para despertar a curto prazo processos de aprendizagem no sistema político ou para reorientar os processos de decisão." (HABERMAS, 1997, p. 107). A respeito de seu papel e espaço na mídia, Habermas (1997, p. 110) entende que "atores coletivos, que operam fora do sistema político ou fora das organizações sociais e associações" também têm menos chances de influenciar o conteúdo dos meios de comunicação e os posicionamentos por eles sustentados, principalmente no que tange a debates que extrapolam o leque de opiniões "equilibrada, pouco flexível e limitada centristicamente" como é o dos grandes veículos de comunicação de acordo com o autor. Novamente, o feminismo pode ser encaixado neste perfil.

Esta limitação ocorre graças à forma como a produção de conteúdo nos grandes veículos de comunicação é organizada. Habermas (1997, p. 110) descreve o processo da seguinte maneira:

[...] a apresentação de notícias e comentários segue conselhos e receitas dos especialistas em propaganda. A personalização das questões objetivas, a mistura entre informação e entretenimento, a elaboração episódica e a fragmentação de contextos formam uma síndrome que promove a despolitização da comunicação pública.

Habermas reconhece o pessimismo desta premissa a respeito dos meios de comunicação, a qual ele associa diretamente com a teoria da indústria cultural ou com aquilo que ele chama de "sociologia da comunicação de massa" (HABERMAS, 1997, p. 113). Para ele, a forma de se romper com este ciclo seria via mobilização, um movimento que faça com que a esfera pública saia de seu repouso. Através da mobilização, "as estruturas sobre as quais se apoia a autoridade de um público que toma posição começam a vibrar. E as relações de forças entre a sociedade civil e o sistema político podem sofrer modificações." (HABERMAS, 
1997, p. 113). É a partir desta concessão que podemos compreender melhor o momento atual vivido pelo feminismo de acordo com a teoria habermasiana das esferas públicas.

Tendo escrito seu trabalho originalmente em 1962, Habermas falava de um cenário em que a internet não existia, de modo que ele foi capaz de traçar o caminho que ela poderia percorrer como suporte para que grupos fora das estruturas de poder levassem suas demandas e discussões a público, desconhecendo, contudo, os meios através dos quais esta trajetória seria percorrida. Através do exemplo da hashtag \#primeiroassédio, vimos como a mobilização feminista empreendida na internet foi capaz de chamar a atenção de grandes veículos de comunicação.

Em 2015, além da iniciativa ter sido noticiada de forma pontual nos principais portais de notícia do país, o movimento chamado de "primavera das mulheres" foi reportagem de capa de suas revistas semanais, Isto É e Época, ambas de circulação nacional que ocupam, respectivamente, o segundo e o terceiro lugar no número de tiragem com relação às revistas semanais brasileiras de acordo com dados de 2014, apurados pela Associação Nacional de Editores de Revista (2014). Em setembro de 2014, a revista Época, da editora Globo, circulou 390.709 exemplares, enquanto a revista Isto É, da Editora 3, circulou 322.518 exemplares. As duas reportagens fizeram um breve histórico do movimento feminista no Brasil até aquele momento, citando eventos e iniciativas supostamente responsáveis pelo boom midiático do feminismo naquele momento, contexto no qual é possível encaixar a hashtag \#primeiroassédio e o trabalho de Juliana de Faria à frente do Think Olga, citado nas duas revistas.

É preciso reconhecer, como o próprio Habermas (1997, p. 116) o faz, que ao chegar à esfera pública midiática massificada, os temas têm que passar por sua "abordagem controversa", uma vez que há os interesses privados e políticos que precisam ser consideramos quando falamos dos grandes jornais e revistas. No entanto, tomando como referência os trabalhos das revistas Isto É e Época, é possível observar que o que foi reportado nos textos encontra muita coerência tanto nas teorias feministas como nos conteúdos desenvolvidos pelos blogs e sites feministas.

Este cuidado de apuração pode ser interpretado também como um reflexo da internet como aponta Soter $(2015$, s.p.) ao afirmar que

com a visibilidade das próprias feministas na mídia independente e nas redes sociais é mais difícil permitir que a tentativa de mudança de lado da mídia tradicional ocorra Para o autor toda vez que mais uma celebridade declara não ser feminista, uma série de feministas insistem na importância do movimento. Quando a Time incluiu 'feminism' como palavra a ser banida, por exemplo, a reação negativa do público levou a revista a um pedido público de 'mais ou menos desculpas

Ou seja, os veículos sabem que o conteúdo que produzirem está sujeito à avaliação e escrutínio dos grupos feministas, que se manifestarão caso não concordem com o que foi dito com potencial para gerar ações de resposta que podem prejudicar a imagem da publicação.

Embora a literatura consultada nos mostre que não se pode, ainda, falar a respeito de um novo feminismo ou de uma quarta onda do movimento, uma vez que não houve uma mudança de pensamento ou novo marco teórico que o justifique, o que é possível identificar como novidade entre o feminismo que era construído entre o fim da do século XX até meados de 2010 é a presença de um novo suporte: a internet. Na forma de web 2.0, a internet permite que usuários produzam conteúdo e interajam com ele, através de comentários, grupos de discussão e principalmente de compartilhamento e construção colaborativa de discussões Esta configuração em rede, já descrita por Castells (2003, p. 7), torna-se cara ao feminismo ao 
permitir "execução descentralizada, expressão individualizada e comunicação global". Assim, as diversas vozes presentes no feminismo encontram espaço, público, e podem alcançar pessoas em uma escala global.

Por fim, é importante considerar que essa atenção midiática recebida pelo feminismo não é um fenômeno novo. Em Backlash, Faludi (1991) descreve alguns momentos na história dos Estados Unidos durante o século XX em que o movimento feminista ganhou destaque nas esferas públicas, como, por exemplo, durante a Segunda Guerra Mundial, em que tais ideias ganharam força a partir do momento em que as mulheres tiveram a chance de ocupar mais espaço no mercado de trabalho então defasado por causa dos esforços de guerra; o mesmo aconteceu durante os anos 60, em que as ideias feministas pegaram embalo no movimento pelos direitos civis e a contracultura que marcou a década.

Atualmente, graças ao potencial de alcance e engajamento da web, tais movimentações feministas que descrevemos chamam a atenção da grande mídia, o que coloca o feminismo no centro das atenções dos jornalistas novamente. Tal situação de buscar e obter atenção é explicada por Soter $(2015$, s.p.) ao afirmar que

É um ciclo, que se repete e se renova, trazendo à tona as demandas do movimento que são, naquele momento, consideradas mais pertinentes. Felizmente, esse ciclo também permite que cada novo 'ponto alto' do feminismo se construa em cima do anterior, desenvolvendo e evoluindo arepercussão positiva do assunto.

Deste modo, o que vivemos é mais uma manifestação desse ciclo, que com o potencial da web tem a oportunidade de se expandir e atingir esferas públicas de uma forma diferente, mais ampla, e o desafio que se observa é a manutenção desse interesse e o avanço das discussões para as esferas políticas da sociedade, de modo que as ideias possam ir além dos discursos e representações midiáticas e se sedimentem em mais conquistas sociais que nos levem a uma realidade mais igualitária para as mulheres na sociedade.

\section{Referências}

ADICHIE, Chimamanda Ngozi. Sejamos todos feministas. São Paulo: Companhia das Letras, 2014.

BEAUVOIR, Simone de. O segundo sexo: Fatos e mitos. São Paulo: Difusão Européia do Livro, 1970.

O segundo sexo: A experiência vivida. São Paulo: Difusão Européia.

CASTELLS, Manuel. A Galáxia Internet: reflexões sobre a Internet, negócios e a sociedade. Zahar, 2003.

COHEN, J. L. \& ARATO, A. Civil Society and Political Theory. Cambridge/Mass, 1992

FALUDI, Susan. Backlash: O contra-ataque na guerra não declarada contra as mulheres. Rio de Janeiro: Rocco, 2001. 
FRASER, Nancy. Rethinking the public sphere: A contribution to the critique of actually existing democracy. Social text, p. 56-80, 1990.

HABERMAS, Jürgen. Direito e democracia: Entre Facticidade e Validade, vol. II. Rio de Janeiro: Tempo Brasileiro, 1997

HABERMAS, Jürgen. Mudança estrutural da esfera pública: investigações quanto a uma categoria da sociedade burguesa. Rio de Janeiro: Tempo Brasileiro, 2003.

HANSEN, Messiluce da Rocha. Esfera pública midiática: Um estudo a partir dos princípios do discurso público e do modelo de democracia deliberativa habermasiana. 2009. 358 f. Tese (Doutorado) - Curso de Ciências Sociais, Universidade Federal da Bahia, Salvador, 2009. Cap. 4.

KENSKI, Rafael. Jornalismo de dados: análise da \#primeiroassedio. 2015. Disponível em: < https://www.linkedin.com/pulse/jornalismo-de-dados-an\%C3\%A 7 lise-da-primeiroassedio-rafael-kenski>. Acesso em 28 nov. 2015.

MOSCHKOVICH, Marília. Existe, então, um "novo" feminismo? 2014. Disponível em: <http:// outraspalavras.net/posts/existe-entao-um-novo-feminismo/>. Acesso em: 28 nov. 2015.

NARVAZ, Martha Giudice; KOLLER, Sílvia Helena. Metodologias feministas e estudos de gênero: articulando pesquisa, clínica e política. Psicologia em Estudo, v. 11, n. 3, p. 647-654, 2006.

PERLATTO, Fernando. Habermas, a esfera pública e o Brasil. Revista Estudos Políticos, v. 4, p. 78-94, 2012.

PINTO, Céli Regina Jardim. Uma história do feminismo no Brasil. São Paulo: Editora Fundação Perseu Abramo, 2003.

SOTER, Sofia. Feminismo na rede: arma de longo alcance. Disponível em: <http://pontoeletronico.me/2015/feminismo-na-rede/s. Acesso em: 28 nov. 2015.

TELES, Maria Amélia de Almeida. Breve história do feminismo no Brasil. São Paulo: Brasiliense, 1993

Recebido: 20/08/2018

Aceito: 30/70/2018 